\title{
Tye's new take on the puzzles of consciousness
}

Torin Alter [forthcoming in Analysis Reviews]

Physicalism, according to which consciousness is an entirely physical phenomenon, faces serious challenges. Michael Tye’s Consciousness Revisited: Materialism without Phenomenal Concepts (MIT Press, 2009) tries to answer four of them: the knowledge argument (Jackson 1982), the explanatory gap argument (Levine 1983), the hard problem of consciousness (Chalmers 1995), and the zombie argument (Chalmers 2002,2010 ). Physicalist responses to those challenges often appeal to doctrines about phenomenal concepts-concepts that express phenomenal qualities from the perspective of the experiencing subject. In earlier work (Tye 1995, 2000), Tye developed a response of that sort. But now he argues that no such response can succeed, and he develops an alternative line of defense.

Consciousness Revisited is provocative and significant. After providing a brief overview, I will critically examine some of its main arguments concerning phenomenal concepts, the knowledge argument, and the zombie argument.

\section{Overview}

Tye's reasoning in Consciousness Revisited has critical and constructive components. His main critical aim is to refute the phenomenal concept strategy for defending physicalism. Along the way, he criticizes various accounts of phenomenal concepts, such as the view that phenomenal concepts contain their referents as constituents (Papineau 2000); the view that phenomenal concepts are recognitional concepts 
(Loar 1997); and other such views. And he criticizes several doctrines closely connected to the four challenges mentioned above, such as the view, defended by David Chalmers and Frank Jackson (2001), that ordinary macroscopic truths are $a$ priori deducible from microphysical truths. On the constructive side, having rejected the phenomenal concept strategy, he develops an alternative way of defending physicalism - a way in which acquaintance knowledge plays a central role.

In the next three sections, I will discuss Tye's main objections to the phenomenal concept strategy, the Chalmers/Jackson view about a priori deducibility, and Chalmers' version of the zombie argument. I will argue that none of these objections succeeds. Then I will raise a problem for Tye's alternative strategy for defending physicalism.

Consciousness Revisited covers a wide range of topics that I will not discuss. These include: how phenomenal consciousness relates to self-representation, creature consciousness, and consciousness of things; the commitments of and motivations for physicalism; the nature of perceptual content; the philosophical significance of change blindness; the nature of privileged access; and several others.

\section{The phenomenal concept strategy}

To understand how Tye conceives of the phenomenal concept strategy, consider its application to the knowledge argument, with which I will assume familiarity. In his view, the knowledge argument challenges physicalists to explain, without positing nonphysical properties, how Mary could "make a discovery" (xii) when she leaves the black-and-white room. He sees the phenomenal concept strategy as answering 
this challenge by saying that her discovery consists in her acquiring phenomenal color concepts. This new concepts explanation implies that phenomenal concepts have rather demanding possession conditions: pre-release Mary lacks them despite her extraordinary reasoning capacity and comprehensive physical knowledge. But the explanation appears to be neutral on whether the phenomenal properties to which those concepts refer are physical. If the explanation is neutral in this way, then her epistemic progress does not threaten physicalism after all.

Tye argues that the phenomenal concept strategy falls prey to social externalism (Burge 1979, Putnam 1975) about phenomenal concepts. ${ }^{\text {i Social }}$ externalism is usually applied to nonphenomenal concepts such as arthritis. On this view, you might possess the concept of arthritis even if your conception of that disease—roughly, your set of associated beliefs—is highly inaccurate or deeply impoverished. The concept is yours but, if you are like most people, you are willing to defer to experts regarding its extension. Tye argues that social externalism is true of phenomenal concepts too. Here the "experts" are not necessarily scientists but instead are people who, unlike pre-release Mary, have had color experiences. But that detail does not matter for Tye's purposes. If social externalism is true of phenomenal concepts, then Mary could acquire phenomenal color concepts by acquiring words her interlocutors outside the room use to express such conceptsjust as nonchemists can acquire the concept of water by acquiring a word, such as "water," that expresses the concept in their linguistic community. She would then acquire such concepts before leaving the room. And this, Tye infers, undermines the phenomenal concept strategy. 
However, not all versions of the strategy rely on the new concepts explanation. One that may attacks the knowledge argument's epistemic premise: the premise that, roughly put, there are phenomenal truths that cannot be a priori deduced from the complete physical truth. Against this premise, some phenomenal concept strategists argue that, although Mary learns new truths when she leaves the room, this is not because those truths cannot be deduced from what she knows but rather because doing the deduction would require having the concepts she lacks (Kirk 2005). That version of the strategy does seem to rely on the new concepts explanation.ii

Another, more popular version of the strategy attacks a different premise of the knowledge argument: the metaphysical premise that, roughly put, if the epistemic premise is true then there are phenomenal truths that are not metaphysically necessitated by the complete physical truth. Here the strategy is to accept the epistemic premise but explain it in terms of epistemic features of phenomenal concepts rather than metaphysical features of the properties those concepts pick out. However, these epistemic features need not concern the possession conditions of those concepts. They might instead concern the inferential relationship between phenomenal concepts and physical concepts. This is in fact how most phenomenal concept strategists—including Brian Loar (1997), David Papineau (2000), and others—-tend to argue. For example, Christopher Hill (1997) argues roughly that phenomenal and physical concepts play distinct functional roles in relevant cognitive systems and that the distinct roles are mistaken for distinct properties playing those roles. 
Indeed, concerns about the possession conditions for phenomenal concepts could be seen as a distraction from the knowledge argument's main challenge to physicalism. Consider Mary after she leaves the room, sees red, and acquires the phenomenal redness concept. At that point, she knows various truths involving that concept. But even then, plausibly, she cannot deduce such truths from the complete physical truth alone. Rather, her knowledge of those truths relies on introspection (Chalmers 2004, 284-85; Stoljar 2005, section 4). Here the new concepts explanation is irrelevant. Yet most versions of the phenomenal concept strategy would still apply.iii

\section{A priori deducibility}

Tye believes that phenomenal concepts "are a priori irreducible to physical concepts" (56). But he thinks the same is true of "many, many concepts that have nothing to do with phenomenal concepts" (56). For example, he thinks water is $a$ priori irreducible to physical concepts. And he opposes his view to that of Chalmers and Jackson (2001) whose reasoning he summarizes as follows:

[W]e can know a priori that if there is a watery stuff of our acquaintance in place $p$ then there is water in place $p$. This will enable us to deduce $a$ priori that there is water in place $p$ from the microphysical facts and the indexical facts, if we can deduce $a$ priori that there is a watery stuff of our acquaintance in place $p$ from those facts. ${ }^{\text {iv }}$ (62)

Tye responds by rejecting the claim that it is possible to a priori deduce ordinary macroscopic claims (such as the claim that there is water in place $p$ ) from 
the microphysical and indexical facts. He notes that watery stuff is characterized in terms of concepts such as liquid, clear, colorless, etc. And he argues that such concepts are no more linked a priori to microphysical concepts than is water. Those concepts, he says, belong to "the manifest image" (Sellars 1956), and the manifest image

is not neatly and hierarchically organized, with the lowest-level concepts themselves having a priori sufficient conditions for their application using concepts from the scientific image (and the microphysical scientific image in particular).

The passage continues,

The game Chalmers and Jackson are playing is called "passing the buck." But the buck has to stop somewhere. For there to be any plausibility at all to the Canberra [Chalmers/Jackson] program, we would need...to see specific cases in which we can move $a$ priori from purely microphysical claims (supplemented by indexical information) to claims in the manifest image. Chalmers and Jackson fail to provide us with any such cases. (62-3)

Tye's objection is puzzling. On the Chalmers/Jackson view, the deduction base- the conjunctive truth from which, they claim, it is possible to a priori deduce ordinary macroscopic truths-includes not only the complete microphysical truth $P$ and relevant indexical information $I$ but also the complete phenomenal truth $Q$ (plus $T$, a second-order "that's all" truth). $Q$ specifies "the phenomenal states and properties instantiated by every subject bearing such states and properties, at every 
time" along with "any fundamental principles that lawfully govern phenomenal states or that connect phenomenal states with physical states" (Chalmers and Jackson 2001, 319).

Tye does not mention $Q$, and this omission casts doubt on his "passing the buck" objection. $Q$ plays a vital role in Chalmers and Jackson's reasoning. In particular, together with $I$, it provides the reasoner with complete information about how, for example, the stuff located at place $p$ appears perceptually to her and all other subjects. If the reasoner knows all of that, plus everything in $P$ (and $T$ ) then (assuming adequate reasoning capacities) why couldn't she form concepts "in the manifest image" such as clear or liquid? Tye owes us an argument here-an argument that takes $Q$ into consideration.v

\section{Zombies}

After criticizing three unattributed versions of the zombie argument, Tye criticizes a version developed by Chalmers $(2002,2010)$. The latter begins with the premise that a zombie world—a world that lacks consciousness but is a minimal physical duplicate of the actual world—is ideally primarily positively conceivable. Let me briefly explain this terminology.

A hypothesis $H$ is ideally conceivable if $H$ is conceivable on ideal rational reflection. $H$ is primarily conceivable if it is a priori conceivable that $H$ is actually the case, i.e., if a priori $H$ could turn out to be true. For example, plausibly, it is primarily conceivable that water lack hydrogen, even if, as Kripke (1972) argues, this is metaphysically impossible. $H$ is positively conceivable if one can form a positive 
conception in which $H$ obtains. For example, to positively conceive of Timo Boll winning the 2009 ITTF World Championship, one might imagine a situation in which he beats Wang Hao in the finals.

So, Chalmers' premise says that on ideal a priori reflection it is possible to form a positive conception in which the zombie-world hypothesis is actually the case. According to Tye, Chalmers infers from that premise that the zombie-world hypothesis is metaphysically possible and therefore that physicalism is false. ${ }^{\mathrm{vi}}$

Tye argues that if Chalmers' argument were sound then the following reasoning would also be sound. It is ideally primarily positively conceivable that there be a necessarily existing god, a god who exists in all possible worlds. It is also ideally primarily positively conceivable that there be a world in which no god exists. Therefore, it is metaphysically possible both that there be a necessarily existing god and that no god exist. By S5, it follows that there is a necessarily existing god and that no such god exists-a contradiction. Thus, Tye concludes, "something has gone very wrong" (152).

Stephen Yablo (1999) brings essentially the same reductio against Chalmers' argument.vii Chalmers' response to Yablo is straightforward:

In response, I deny that a necessarily existing god is ideally conceivable. A god's existence may be conceivable, but to conceive of a god's necessary existence is much harder, especially given its conceivable nonexistence. (Chalmers 2002, 189)

I would add that there are plausible ways to explain why a necessarily existing god might seem (ideally primarily positively) conceivable even if it is not. 
For example, one might confuse the claim that a necessarily existing god is (ideally primarily positively) conceivable with the claim that we do not know with complete certainty that a necessarily existing god does not exist. The latter claim seems hard to deny. But it does not entail the former, more dubious claim. In any event, Chalmers' response seems adequate. At least, it shifts the burden of proof. Unfortunately, Tye does not mention Chalmers' response (though he does cite Yablo 1999). He should provide reasons to believe that a necessarily existing god is ideally primarily positively conceivable-reasons that take Chalmers' response into account.

In Tye's view, assessing whether the zombie-world hypothesis is ideally primarily positively conceivable requires first determining whether physicalism is a better theory than its rivals. He compares the zombie hypothesis with "the thesis $T$, that the only entities that have being are those that exist" (152), and he writes,

Ontic pluralists deny this thesis, but its advocates take it to be a necessary truth. Is $\sim T$ positively conceivable? Is $T$ positively conceivable? ...If the best theory with respect to the nature of being and existence is one that holds that to be is to exist, then we should embrace it and accept, as a consequence, that $T$ is positively conceivable whereas $\sim T$ is not. ...Thus, in the case of a zombie replica of the actual world, if the best theory with respect the nature of mentality is the physicalist thesis, as I maintain, we should deny that a zombie replica is positively conceivable. (152-53) viii

However, using the conceivability of a hypothesis to test a philosophical theory is a common and arguably indispensible practice (Stoljar 2006). To be sure, 
the practice is inappropriate in some cases, and Tye's example of $T$ and ontic pluralism might be one such case. But his comparison to the zombie-world hypothesis is misleading. $T$, a universal generalization about the connection between being and existence, is itself a theory or at least a component of one. Also, without any explanation of the intended meaning of "being" and "existence," T"s content is obscure. For these reasons, it is not clear what conceiving $T$ would consist in. By contrast, the zombie-world hypothesis is neither a theory nor a component of one. It is rather a description of (or a hypothesis about) a specific scenario. Also, Chalmers explains the relevant concepts, such as the concept of physical duplication, clearly enough to leave little doubt about what the scenario is supposed to be. The differences between this case and the case of $T$ are striking in ways that bear directly on the conceivability issue. Therefore, Tye's comparison fails to reveal a problem in Chalmers' reasoning.

\section{Acquaintance}

Tye invokes Bertrand Russell's (1912) distinction between "knowledge by acquaintance" and "knowledge by description" to answer three of the four challenges to physicalism that he considers (the distinction does not appear to play any role in Tye's objections to the zombie argument). I will focus on how he uses the distinction to answer the knowledge argument. The objection I will present applies mutatis mutandis his use of the distinction to answer the explanatory gap argument and the hard problem of consciousness. 
According to Tye, one becomes acquainted with a thing by encountering it in experience. Also on his view, being acquainted with something neither implies nor is implied by knowing truths about that thing. He writes,

I am acquainted with the color red, the city of Athens, the Apple computer at which I am now typing, the feeling of pain, the urge to gamble a large sum of money, and the feeling of jealousy. I have encountered (or am encountering) all of these things in experience. Where I have not encountered a thing in experience, as is the case with the city of Istanbul and the shape of a chiliagon, I am not acquainted with it in the relevant sense of 'acquaintance'. In such cases, I may have familiarity with the thing, and thereby have knowledge of it. But familiarity of this sort essentially involves knowing (or at least believing) truths about the thing, whereas acquaintance with a thing, I as understand it, does not. One can be acquainted with a thing (in my sense, following Russell) without knowing any truths about it. (101)

Tye proposes an acquaintance hypothesis to explain the epistemic progress Mary makes upon leaving the black-and-white room: when she leaves the room, she becomes acquainted with the phenomenal character of seeing red. He writes,

Mary in her room knows all the physical facts about the subjective character of the experience of red. But...she does not know the thing that is the subjective character of the experience of red. She is not acquainted with that thing. When she leaves the room and becomes acquainted with the phenomenal or subjective character of the experience of red thereby she knows it. This is genuinely new knowledge, logically distinct from her earlier factual knowledge. (131-32) 
According to Tye, the acquaintance hypothesis plausibly explains Mary's epistemic progress in a way that is consistent with physicalism, thereby relieving "the pressure on the materialist created by the failure of the phenomenal-concept strategy" (xii).

Tye's proposal raises a question: when Mary becomes acquainted with the phenomenal character of seeing red, does she also (perhaps as a result) gain information? Either she does or she does not, and either way there is trouble. Let us consider the horns of this dilemma in turn. .x $^{\text {. }}$

Horn 1: Mary gains information in addition to (or because of her gaining) acquaintance knowledge. ${ }^{\mathrm{x}}$ The problem with horn 1 is obvious. If Mary gains information, then analyzing her epistemic growth in terms of acquaintance fails to blunt the force of the knowledge argument. It does not matter if the reason she gains information is that she gains acquaintance knowledge. The question remains: how can the information she gains be physical, if she knows all physical information before leaving the room? And why doesn't the fact that she gains information establish the knowledge argument's epistemic premise?

Tye might reply that acquaintance gives Mary a new perspective on information already in her possession. Some passages seem to suggest that idea. For example, he says that acquaintance puts her in the position to entertain a proposition "in a phenomenal way via her acquaintance with the color red" (133)— a proposition that she knows in a different, physical way. However, it is hard to know what to make of this move. So elaborated, the acquaintance hypothesis seems 
suspiciously similar to the strategy he now rejects: the phenomenal concept strategy.

Horn 2: Mary gains only acquaintance knowledge and no information. Horn 2 has a different but equally serious problem. On horn 2 , the acquaintance hypothesis does not do justice to the intuition that when Mary leaves the room she gains knowledge in the substantial sense that she seems to. To see this, consider the Murry case:

Murry learn all truths about New York City without ever having been there, including the truths about how the city appears and the phenomenal states visiting would cause him to have. He learns this partly through reading books and partly by means of his using a virtual reality system akin to the Holodeck depicted in Star Trek: The Next Generation. Finally, after acquiring all of that information, Murry visits New York and experience it for himself. ${ }^{\mathrm{xi}}$

Murry does not become acquainted (in Tye's sense) with New York until he visits. Even so, when he visits he should find nothing particularly surprising or enlightening. A "Ho-hum" reaction would be appropriate. Matters are otherwise with Mary when she leaves the room and (we will assume) becomes acquainted with the phenomenal character of seeing red. As Tye himself points out, she seems to make a substantial discovery. In her case, a "Ho-hum" reaction would not be appropriate.

Let me be clear. I am not here denying that acquaintance knowledge is a genuine form of knowledge. Rather, I am denying that Mary's epistemic progress consists entirely in coming to stand in the acquaintance relation to something 
without gaining any information whatsoever. If the latter claim seems initially plausible, this might be because becoming acquainted with something normally provides information about that thing. That is, we might be tacitly assuming that acquaintance always provides such information. But the latter assumption does not hold on horn 2 .

Thus, on horn 1 the acquaintance hypothesis fails to help physicalists answer the knowledge argument, and on horn 2 the hypothesis is implausible. ${ }^{x i i}$ Evidently, physicalists have more work to do. xiii

\section{References}

Alter, T. (n. d.) Social externalism and the knowledge argument.

Alter, T. 1998. A limited defense of the knowledge argument. Philosophical Studies 90: 35-56.

Alter, T. and Howell, R. J. 2009. A Dialogue on Consciousness. New York: Oxford University Press.

Ball, D. 2009. There are no phenomenal concepts. Mind 118: 935-62.

Burge, T. 1979. Individualism and the mental. Midwest Studies in Philosophy 4: 73-121.

Chalmers, D. J. 2010. The two-dimensional argument against materialism. In his The Character of Consciousness. New York: Oxford University Press: 141-91.

Chalmers, D. J. 2004. Phenomenal concepts and the knowledge argument. In There's Something about Mary: Essays on Phenomenal Consciousness and Frank Jackson's Knowledge Argument, P. Ludlow, D. Stoljar, and Y. Nagasawa (eds.). Cambridge: MIT Press: 269-98.

Chalmers, D. J. 2002. Does conceivability entail possibility? In T. Gendler and J. Hawthorne (eds.), Conceivability and Possibility. New York: Oxford University Press: 145-200. 
Chalmers, D. J. 1995. Facing up to the hard problem of consciousness. Journal of Consciousness Studies 2: $200-19$.

Chalmers, D. J. and Jackson, F. 2001. Conceptual analysis and reductive explanation. Philosophical Review 110: 315-61.

Conee, E. 1994. Phenomenal knowledge. Australasian Journal of Philosophy 72: 136-50.

Hill, C. 1997. Imaginability, conceivability, possibility, and the mind-body problem. Philosophical Studies 87: 61-85.

Howell, R. J. 2008. The two-dimensionalist reductio. Pacific Philosophical Quarterly 89: 348-58.

Jackson, F. 1982. Epiphenomenal qualia. Philosophical Quarterly 32: 127-36.

Kirk, R. 2005. Zombies and Consciousness. New York: Oxford University Press.

Levine, J. 1983. Materialism and qualia: the explanatory gap. Pacific Philosophical Quarterly 64: 35461.

Kripke, S. 1972. Naming and necessity. In G. Harman and D. Davidson (eds.), The Semantics of Natural Language. Dordrecht: Reidel: 253-355.

Loar, B. 1997. Phenomenal states (revised version). In N. Block, O. Flanagan, and G. Güzeldere (eds.), The Nature of Consciousness. Cambridge, MA: MIT Press: 597-616.

Papineau, D. 2002. Thinking about Consciousness. New York: Oxford University Press.

Putnam, H. 1975. The meaning of 'meaning'. In K. Gunderson (ed.) Language, Mind and Knowledge. Minnesota Studies in the Philosophy of Science VII, University of Minnesota Press. Reprinted in Putnam's Philosophical Papers, Volume 2: Mind, Language and Reality: 215-71.

Russell, B. 1912. The Problems of Philosophy. New York: Oxford University Press. 
Sellars, W. 1956. Empiricism and the philosophy of mind. Minnesota Studies in the Philosophy of Science 1: 253-329.

Stoljar, D. 2006. Ignorance and Imagination: The Epistemic Origin of the Problem of Consciousness. New York: Oxford University Press.

Stoljar, D. 2005. Physicalism and phenomenal concepts. Mind and Language 20: 469-94.

Stoljar, D., and Nagasawa, Y. 2004. Introduction to There's Something about Mary: Essays on Phenomenal Consciousness and Frank Jackson's Knowledge Argument. Cambridge, MA: MIT Press: 136.

Tye, M. 2009. Consciousness Revisited: Materialism without Phenomenal Concepts. Cambridge: MIT Press.

Tye, M. 2000. Consciousness, Color, and Content. Cambridge, MA: MIT Press.

Tye, M. 1995. Ten Problems of Consciousness: A Representational Theory of the Phenomenal Mind. Cambridge, MA: MIT Press.

Yablo, S. 1999. Concepts and consciousness: comments on Chalmers, The Conscious Mind. Philosophy and Phenomenological Research 59: 455-64.

\footnotetext{
i Tye's argument is essentially the same as Derek Ball's (2009).

ii However, elsewhere (Alter n. d.) I argue that the new concepts explanation might not be essential even to this version of the phenomenal concept strategy.

iii Tye's argument turns on the possibility of bearing epistemic relations such as knowledge and belief to propositions under a merely deferential grasp of the relevant concepts. Elsewhere (Alter n. d.) I argue that such a possibility is beside the point. I argue that both the knowledge argument and the phenomenal concept strategy can be reformulated, without substantial loss, in terms of epistemic relations to propositions that, by stipulation, require a nondeferential grasp on the relevant concepts.
} 
iv Watery stuff is stuff that has the stereotypical macroscopic features of water: a colorless, odorless, tasteless liquid, which falls from the sky as rain, etc. Indexical facts are facts expressed with indexicals such as "I" and "now". As Chalmers and Jackson note, adding indexical truths to the entailment base enables the agent doing the a priori reasoning to locate herself-to determine, for example, whether she is on Earth or Twin-Earth.

${ }^{v}$ Additionally, contrary to what Tye implies, Chalmers and Jackson do not argue that one deduces truths involving the water concept by first deducing truths involving the watery stuff concept. They argue that $P Q T I$ itself provides sufficient information to determine conclusively the truth or otherwise of any ordinary macroscopic truth $M$, including the truth that there is water in place $p$. See Chalmers and Jackson 2001, especially section 4.

vi Actually, Chalmers' conclusion is disjunctive: either the zombie world is metaphysically possible (in which case physicalism is false) or Russellian monism is true. Also, his inference invokes other premises that Tye does not mention. However, here these details do not matter much.

vii See also Howell 2008.

viii The passage continues: "What is true instead in this case is that such a replica is negatively conceivable. No amount of a priori reflection rules out the possibility of a zombie replica of the actual world" (153). This is an odd concession. Chalmers argues that the negative ideal primary conceivability of the zombie hypothesis would suffice for the purposes of his argument. ix As Tye acknowledges, his response to the knowledge argument is essentially the same as Earl Conee's (1994). Elsewhere (Alter 1998) I advance an objection against Conee's response similar to the one advanced here. Also, Chalmers presented a version of the objection in a session on Tye's book at the 2008 Pacific Division Meeting of the American Philosophical Association, and the present version was influenced by that presentation. For related argument, see Stoljar and Nagasawa 2004 and Alter and Howell 2009.

${ }^{x}$ Horn 1 seems out of the spirit of Tye's proposal. He emphasizes that Mary gains acquaintance knowledge as opposed to propositional knowledge, and that she comes to know a thing, not a truth. Still, some passages suggest horn 1 . For example, he seems to accept the following view: "...Mary, in 
knowing what it is like to experience red, stands in the knowing-that relation to the fine-grained proposition that this is what it is like to experience red and is in a position to entertain this proposition in a phenomenal way via her acquaintance with the color red. Mary's consciousness of red gives her objectual knowledge by acquaintance of red, and (partly) via that knowledge she knows a certain proposition. ...after she leaves her room Mary knows a certain fact (partly) by knowing a certain entity she did not know in her room..." (133)

xi Here we must make various fanciful assumptions, such as the assumption that Murry has a Marylike intellect and that all the NYC truths are made available to him.

xii Tye connects his views on acquaintance to some of his views on perceptual content. In particular, he connects acquaintance to his view that, "I am conscious of a given entity only if my conscious state is so situated that it enables me to ask "What is that?" with respect to that entity (and it does so solely on the basis of its phenomenology)" (100). One might therefore wonder if this aspect of his position could help him evade horn 1 or horn 2. However, if it does, it is unclear how.

xiii For helpful discussions, I thank David J. Chalmers and Robert J. Howell. I also thank the Philosophy Departments of The University of Alabama and New York University for their support. 